\title{
Natures therapy for COVID-19: Targeting the vital Non-Structural Proteins (NSP) from SARS-CoV-2 with phytochemicals from Indian medicinal plants
}

\author{
Pratap Kumar Parida 1\#, Dipak Paul 1\#, Debamitra Chakravorty 2*\#
}

1 Noor Enzymes Private Limited, 37-B, Darga Road, Kolkata - 700 017, India

2 Novel Techsciences (OPC) Private Limited, 37-B, Darga Road, 1st Floor, Kolkata - 700 017, India

* Corresponding author:

Debamitra Chakravorty, $\mathrm{PhD}$ (Project Lead - Computational Biology)

Novel Techsciences (OPC) Private Limited, 37-B, Darga Road, 1st Floor, Kolkata - 700 017, India

E-mail: dc@noveltechsciences.com

\#All the authors have contributed equally to the paper.

\begin{abstract}
Containing COVID-19 is still a global challenge. It has affected the "normal" world by targeting its economy and health sector. Research is more focused on finding a cure to this disease and is less concerned about other life threatening diseases like cancer. Thus we need to develop a medical solution at the earliest. In this context the present work aimed to understand the efficacy of 22 rationally screened phytochemicals from Indian medicinal plants obtained from our previous work, following drug-likeness properties, against 6 non-structural-proteins (NSP) from SARS-CoV-2. $100 \mathrm{~ns}$ molecular dynamics simulations were performed and relative binding free energies were computed by MM/PBSA. Further, principal component analysis, dynamic cross correlation and hydrogen bond occupancy were analyzed to characterize protein-ligand interactions. Biological pathway enrichment analysis was also carried out to elucidate the therapeutic targets of the phytochemicals in comparison to SARS$\mathrm{CoV}-2$. The potential binding modes and favourable molecular interaction profile of 9 phytochemicals, majorly from Withania sominifera with lowest free binding energies, against the SARS-CoV-2 NSP targets were identified. It was understood that phytochemicals and repurposed drugs with steroidal moieties in their chemical structures formed stable interactions with the NSPs. Additionally, human target pathway analysis for SARS-CoV-2 and phytochemicals showed that cytokine mediated pathway and phosphorylation pathways were with the most significant p-value. To summarize this work, we suggest a global approach of targeting multiple proteins of SARS-CoV-2 with phytochemicals as a natural alternative therapy for COVID-19. We also suggest that these phytochemicals need to be tested experimentally to confirm their efficacy.
\end{abstract}

Key Words: SARS-CoV-2, India, phytochemicals, molecular dynamics, simulation, binding energy, NSP, Pathway enrichment 


\section{Introduction}

The pandemic COVID-19 (coronavirus disease 2019) has spread to more than 203 countries and territories. Initial reports suggested that $20 \%$ cases are severe but its fast transmission rates has severely impacted world economy and the health care sector causing global panic (Chen et al., 2020, Guan et al., 2020, Huang et al., 2020). SARS-CoV-2 has been related to gastroenteritis, heart failure and respiratory complications. It is also severe in immunocompromised patients, in men independent of age and elderly patients with diabetes, hypertension, cerebral infarction, chronic bronchitis, Parkinson's disease, cardiovascular diseases and cancer (Deng \& Peng, 2020; Guan et al., 2020; Huang et al., 2020; Jin et a. 2020; Islam et al. 2020). Given the severity of the infection, the proposed therapies include targeting viral replication and blocking the virus attachment to human cell receptors by its structural proteins (Wu et al. 2020). Unfortunately, coronavirus vaccines are not yet on the market and large-scale manufacturing capacity for these vaccines does not exist as yet (Amanat et al. 2020). Only two candidate vaccines have reached stage $2 / 3$ clinical trials and one in phase 2 (COVID-19 vaccine tracker, 11 June 2020). Considering economical impact on stock markets in recent times, funding for vaccine production seems to be great investment in the near future (Amanat et al. 2020). In this context development of natural drug therapy can help to contain the spread of the virus. Nature provides a vast library of chemicals yet to be explored and develop drugs for treatment of various viral ailments (Denaro et al., 2019). Research have been conducted in screening natural drugs against SARS-CoV-2 targets (Luo et al. 2020; Pang et al. 2020; Yang et al. 2020; Zhang et al. 2020; Chen et al., 2020; Xu et al., 2020; Zhenming et al. 2020). Some natural products have been shown to possess antiviral activity in the nanomolar concentration leading for further drug development (Islam et al. 2020). In this context, we have also recently presented 66 virtually screened phytochemicals from 55 Indian medicinal plants against 8 SARS-CoV-2 targets (Parida et al. 2020a). We also presented molecular dynamics simulation of screened phytochemicals following drug-likeness properties, against the spike glycoprotein and the main protease- considered to be the most vital targets for drug development for SARS-CoV-2 (Parida et al. 2020b). Interestingly from our previous work and the vast literature that exist for drug development against SARS-CoV-2, it was realized that concentrating only on the spike glycoprotein and the 3CLpro for drug development may result in failure of the drugs in the future due to development of multi drug resistance strains of the SARS-CoV-2 virus as it is prone to high rate of mutations (Pacheti et al. 2020). Therefore, targeting other proteins involved in viral replication complex becomes necessary. In order to 
control SARS-CoV-2 and to overcome future multi drug resistance in this work 6 nonstructural proteins (NSPs) as targets for drug development is being suggested. These NSPs may have conserved roles within the viral lifecycle of SARS-CoV-2 (Littler et al. 2020). The NSPs selected in this study were due to their indispensable nature in the viral life cycle. Other than the main protease NSP5 (3CLpro) vital targets of SARS-CoV-2 considered in this work were Nsp3, NSP9, NSP10, NSP12, NSP15 and Nsp16.

NSP3 is the papain-like proteinase- essential component of replication/transcription complex in coronaviruses. It has also been reported to induce protective immunity by blocking host immune response by inhibiting the expression of innate immunity genes (Fehr et al. 2016). Its conserved macrodomain adopts three-layered $\alpha / \beta / \alpha$ sandwich fold (Lei et al. 2018). This macrodomain is involved in binding of ADP-ribose in most of the corona viruses (Han et al., 2011; Cho et al., 2016). It bears $91.8 \%$ sequence similarity with SARS-CoV-2 NSP3 (Yoshimoto et al. 2020). Another promising target used in this study was NSP 9 (RNA-binding protein) as it is thought to mediate viral replication. NSP9 from SARS-CoV-2 bears $99.1 \%$ sequence similarity with that from SARS-CoV (Yoshimoto et al. 2020). A conserved $\alpha$-helical 'GxxxG' motif and disruption of the motif residues by mutagenesis was reported to reduces both RNA-binding and SARS-CoV viral replication (Sutton et al., 2004; Frieman et al., 2012). NSP10 was chosen as another important drug target as it acts as a cofactor for the activation of the replicative enzyme in SARS-CoV. It is also a nucleic acid-binding protein with two zinc fingers (Joseph et al., 2006, Matthes et al., 2006). NSP10 interacts with NSP14 and NSP16, stimulating 3'-5' exoribonuclease and 2'-O-methyltransferase activities respectively (Bouvet et al. 2014). Its sequence similarity (99.3\%) with SARS-CoV-2 makes it a promising drug target (Yoshimoto et al. 2020). NSP12 or the RNA dependent RNA polymerase has been chosen as an important drug development candidate as it is involved in viral replication, but no specific inhibitors have been found until now (Chu et al. 2006). Therefore, in this work other than the main catalytic pocket of NSP12, NSP12-NSP8 and NSP12-NSP7 interfaces were also chosen as potential targets. NSP8 synthesizes primer- up to six nucleotides in length, for NSP12-RdRp RNA synthesis. Further, the NSP7 acts as a cofactor to enhance the RdRps enzyme activity of NSP12 (Wu et al. 2020). Another interesting SARS-CoV-2 target used in this work was NSP15 with $97.7 \%$ sequence similarity with SARS-CoV (Yoshimoto et al. 2020). This protein was reported to degrade polyuridine sequences and viral dsRNA to prevent host recognitio of the virus to prevent the host immune sensing system from detecting the virus (Hackbart et al. 2020). Furthermore, NSP16 was also targeted for phytochemical drug development as it is a 2'-O-ribose-methyltransferase in SARS-CoV. It is responsible for promoting mRNA 
translation, and protects the viral RNA from getting recognized by immunity mechanisms (Decroly et al. 2011). It bears 99\% sequence similarity with SARS-CoV-2 NSP16.

Briefly it can be said that the aim of the present work was to explore various NSPs from SARS-CoV-2 as promising targets for phytochemicals as drug candidates. In this study, we present the analysis of $100 \mathrm{~ns}$ molecular dynamics trajectories for 6 NSPs from SARS-CoV-2 and their phytochemical complexes. The binding free energy and the interaction dynamics of the phytochemicals were analysed by various computational approaches. Further, the therapeutic efficacy of these phytochemicals were also experimented by biological pathway enrichment analysis. In summary it can be said that targeting these NSPs with phytochemicals can serve to overcome the predicted multi-drug resistance as SARS-CoV-2 which is fast evolving due to its propensity to high mutations.

\section{Methodology}

\section{Molecular Dynamics Simulations and trajectory analyses of the phytochemicals against the vital NSPs of SARS-CoV-2}

Phytochemicals were successfully screened from Indian medicinal plants by molecular docking against 10 SARS-CoV-2 protein target binding sites in our previous work (Parida et al. 2020a). 22 phytochemicals with good docking scores that followed drug like properties against SARS-CoV-2 NSP3, NSP9, NSP10, NSP12, NSP16 and NSP15 were analysed by 100 ns molecular dynamics (MD) simulations (Table 1). The repurposed drugs that had the lowest binding score were also subjected to MD simulations as a control group. All the simulations were carried out with Gromacs 2020.2 software package (Lindahl et al. 2020) with AMBER99SB-ILDN force field and TIP3P water molecules. The force field parameters for the phytochemicals and the repurposed drugs were generated by ACPYPE (AnteChamber PYthon Parser interface) (Silva et al. 2012). Charges were neutralized and system was minimized with 5,000 steps by steepest descent algorithm. The systems were equilibrated by 1 ns position restraint simulations of $1000 \mathrm{~kJ} \mathrm{~mol}^{-1} \mathrm{~nm}^{-2}$ in the NVT and NPT ensembles. Equilibrated systems were used to simulate a 100 ns with no restraint production run. Electrostatic interactions were calculated with Particle-Mesh-Ewald summation (PME) (Darden et al., 1993). Post-MD analyses were performed, this includes root mean square deviation (RMSD), root mean square fluctuations (RMSF), the radius of gyration (Rg) and hydrogen bond occupancy. Molecular Mechanics - Poisson Boltzmann Surface Area (MM-PBSA) was applied on snapshots obtained from MD trajectory to estimate the binding free energy using the GROMACS tool g_mmpbsa (Kumari et al. 2014; Baker et al. 2001). The Principal Component 
Analysis (PCA) was performed using GROMAC v2020.2. Further, Dynamic Cross Correlation Matrix (DCCM) analysis performed using the Bio3D package (Grant et al. 2006).

High Performance Computing resources of Amazon EC2 G4 instances were employed for carrying out computational work on Amazon Web Services cloud computing platform (https://aws.amazon.com) with the help of RONIN interface (https://ronin.cloud/) as an award granted by the COVID-19 High Performance Computing (HPC) Consortium for carrying out this work (https://covid19-hpc-consortium.org/projects).

Table 1: The phytochemicals and their tartgets from SARS-CoV-2

\begin{tabular}{|c|c|c|c|c|}
\hline $\begin{array}{l}\text { *Phytochemicals/ } \\
\text { Repurposed drugs }\end{array}$ & Complexes & \begin{tabular}{|c|} 
Docking \\
Score \\
(Kcal/mol $)$ \\
\end{tabular} & \#2D structure & *Plant Source \\
\hline \multicolumn{5}{|c|}{ NSP 10 (PDB 6w4h) } \\
\hline 27-Hydroxywithanolide B & N10P1 & -8.32 & & $\begin{array}{l}\text { Withania } \\
\text { somnifera }\end{array}$ \\
\hline Anaferine & N10P2 & -6.22 & & $\begin{array}{l}\text { Withania } \\
\text { somnifera }\end{array}$ \\
\hline Baricitinib & N10-R3 & -9.22 & & Repurposed drug \\
\hline \multicolumn{5}{|c|}{ NSP12 D1 (RNA Binding Site) (PDB 6M71) } \\
\hline $\begin{array}{l}\text { 12- } \\
\text { Deoxywithastramonolide }\end{array}$ & $\mathrm{N} 12 \mathrm{~d} 1 \mathrm{P} 1$ & -7.58 & & $\begin{array}{l}\text { Withania } \\
\text { somnifera }\end{array}$ \\
\hline Methylprednisolone & N12d1R2 & -6.54 & & Repurposed drug \\
\hline \multicolumn{5}{|c|}{ NSP12 D2 (NSP12-NSP7 Interface) (PDB 6M71) } \\
\hline Withastramonolide & $\mathrm{N} 12 \mathrm{~d} 2 \mathrm{P} 1$ & -9.72 & & $\begin{array}{l}\text { Withania } \\
\text { somnifera }\end{array}$ \\
\hline Withanolide B & $\mathrm{N} 12 \mathrm{~d} 2 \mathrm{P} 2$ & -9.2 & & $\begin{array}{l}\text { Withania } \\
\text { somnifera }\end{array}$ \\
\hline $\begin{array}{l}\text { 12- } \\
\text { Deoxywithastramonolide }\end{array}$ & $\mathrm{N} 12 \mathrm{~d} 2 \mathrm{P} 3$ & -9.05 & & $\begin{array}{l}\text { Withania } \\
\text { somnifera }\end{array}$ \\
\hline
\end{tabular}




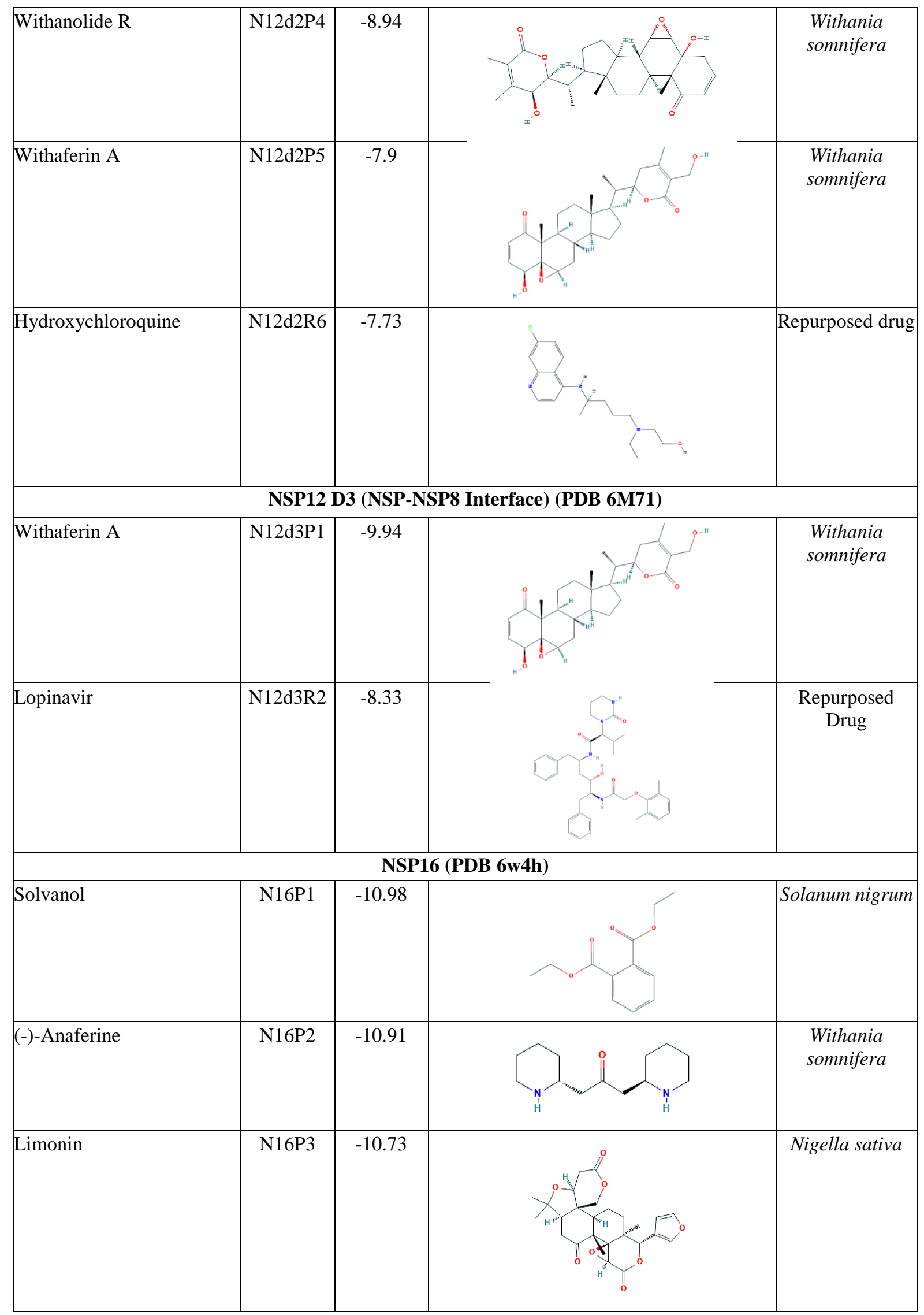




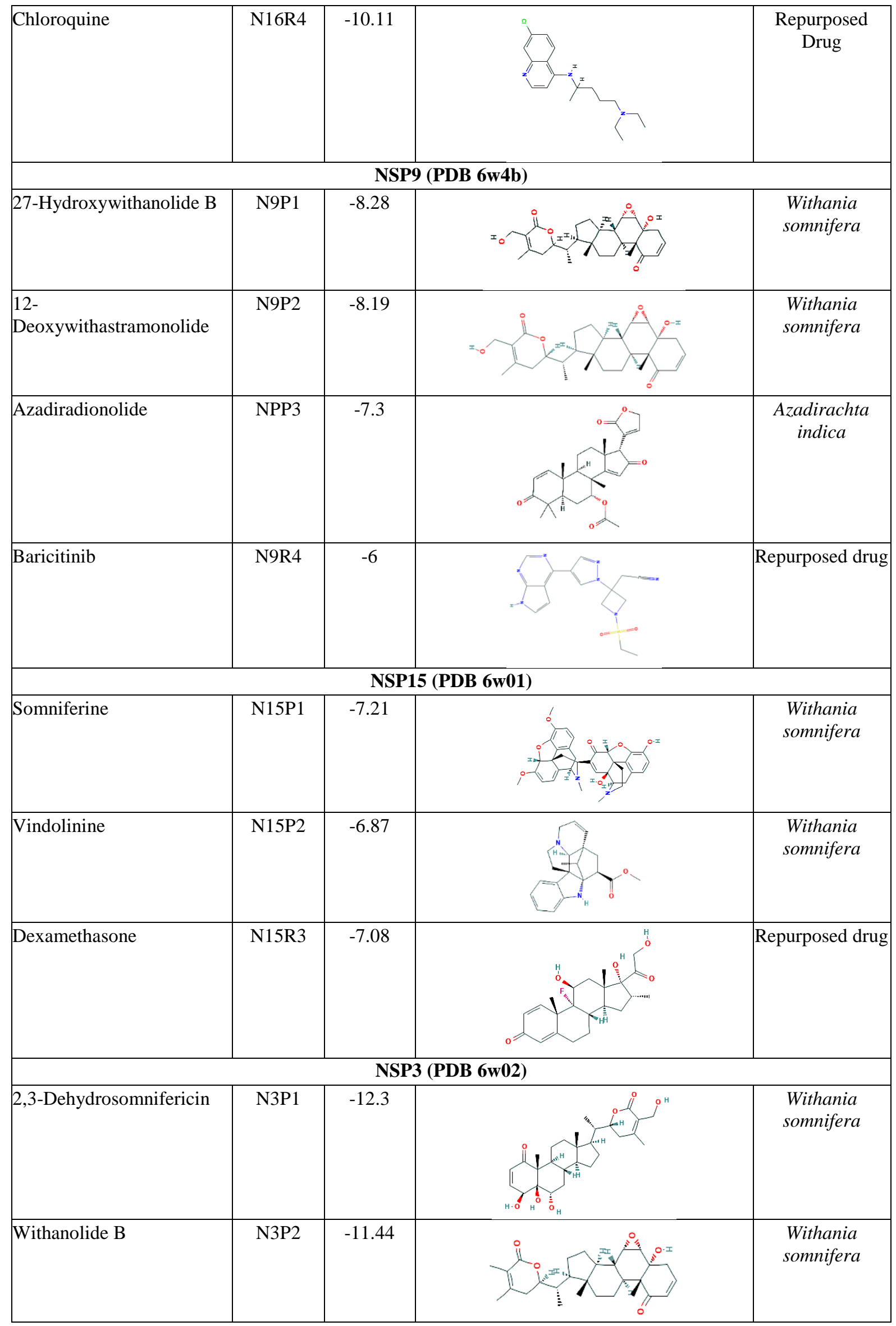




\begin{tabular}{|l|c|c|c|c|}
\hline $\begin{array}{l}\text { 24,25-dihydrowithanolide } \\
\mathrm{D}\end{array}$ & $\mathrm{N} 3 \mathrm{P} 3$ & -10.24 & $\begin{array}{c}\text { Withania } \\
\text { somnifera }\end{array}$ \\
\hline $\begin{array}{l}\text { 27-Deoxy-14- } \\
\text { hydroxywithaferin A }\end{array}$ & $\mathrm{N} 3 \mathrm{P} 4$ & -9.49 & & $\begin{array}{c}\text { Withania } \\
\text { somnifera }\end{array}$ \\
\hline Baricitinib & $\mathrm{N} 3 \mathrm{R} 5$ & -10.38 & & \\
\hline
\end{tabular}

"The phytochemicals (docking scorers) and interacting residues within the binding pocket were identified from a previous work to possess drug likeness properties (Parida et al. 2020a).

\#The 2D images of the phytochemicals were obtained from PubChem Database (https://pubchem.ncbi.nlm.nih.gov/).

\section{Biological pathway enrichment analysis of human protein targets identified for the phytochemicals}

SwissTargetPrediction server was employed to identify top 15 human protein targets of the phytochemicals (Gfeller et al., 2014). Redundancy removal led resulted into 93 target proteins for the phytochemicals. Further, 172 protein targets for human coronavirus were obtained by literature survey (Zhou et al. 2020; Chakrabarty et al. 2020). Enrichr and REVIGO webserver were used for gene ontology (GO) enrichment analysis (Kuleshov et al., 2016; Supek et al., 2011). The generated networks were visualized in Cytoscape v3.8 (Shannon et al., 2003). Enrichr was also employed to calculate the p- values using the Fisher exact test for pathway and database enrichment for Kyoto Encyclopedia of Genes and Genomes (KEGG) pathways and VirusMint databaseichr. VirusMint is database of interactions between viral and human proteins (Chatr-aryamontri et al. 2009). 


\section{Results}

\section{Molecular dynamics simulation trajectory analysis of the NSP complexes}

In this work, 6 NSP and 8 potential drug target sites docked with 22 phytochemicals and 10 repurposed drugs obtained from our previous work, were explored by 100 ns molecular dynamics simulations (Parida et al. 2020a). Throughout this paper the NSP complexes with the phytochemicals and the repurposed drugs have been abbreviated as presented in Table 2 . The binding sites have been illustrated in Figure 1. The binding site of NSP10 and NSP16 were the NSP10-NSP16 binding interface (PDB ID: 6w4h). The binding site in NSP10 (known to stimulate methyl transferase activity of NSP 16 comprised of residues Asn4293-Tyr4349 between helix 1 and helix 3. In NSP 16 it involved residues Lys 6836-Met6839 and Val6842Asp6904 which lies in between helix 3 and $\beta$-sheet A edge $\beta$-strand 4. The inhibitor binding site in NSP9 (involved in viral replication, PDB ID: 6w4b) was the dimerization interface consisting of residue Arg100- Thr110 (helix 1). In NSP 12 (PDB ID: 6m71) three sites were chosen: D1 which is the catalytic pocket; D2: NSP12-NSP7 binding interface and D3: NSP12NSP8 binding interface. In case of NSP15 (PDB ID: 6w01), an uridylate specific endoribonuclease, active site pocket with conserved residues His235, His250, Lys290, Thr341, Tyr343, and Ser294 was the site of inhibitor docking. In NSP3 (PDB ID: 6w02) which is the ATP ribose phosphatase of SARS-CoV-2, the adenosine-5-diphohoribose binding site was the inhibitor docked site. The site was in between $\beta$-strand 3 of $\beta$-sheet B- helix 2 and strand 3 of $\beta$-sheet A and helix 7. The details of the virtual screening of these 8 target sites can be found in Our previous work (Parida et al. 2020a). 

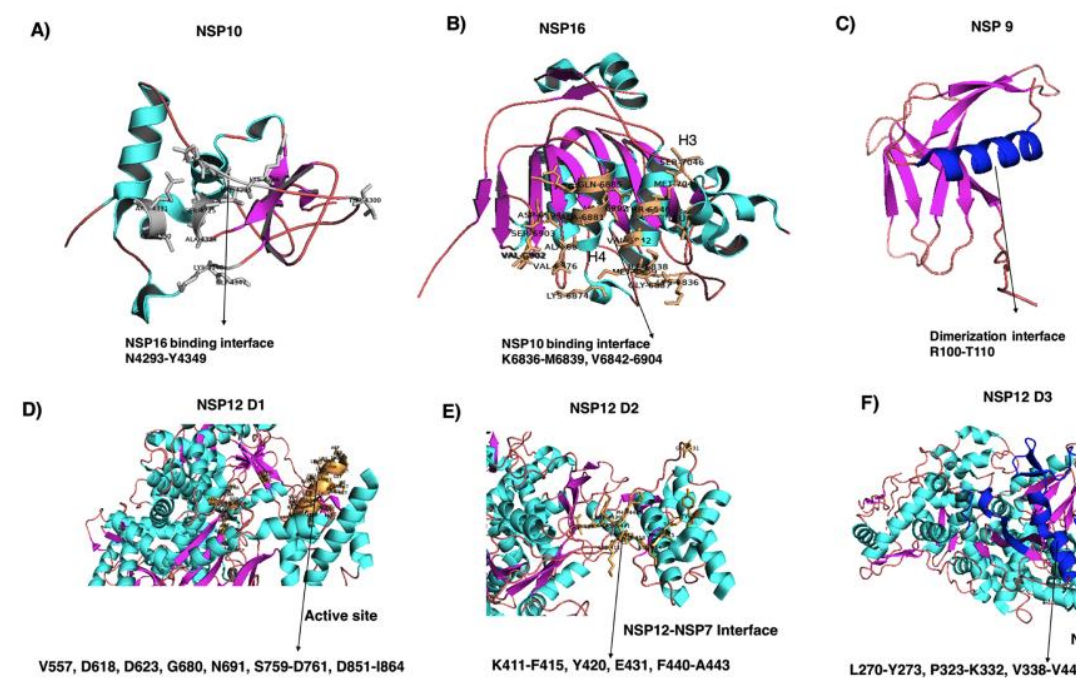

E)

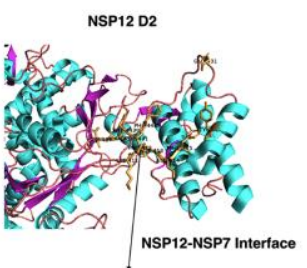

G)

NSP 15

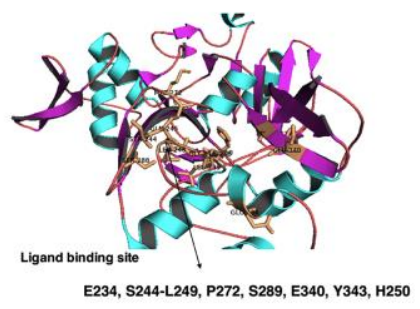

H)

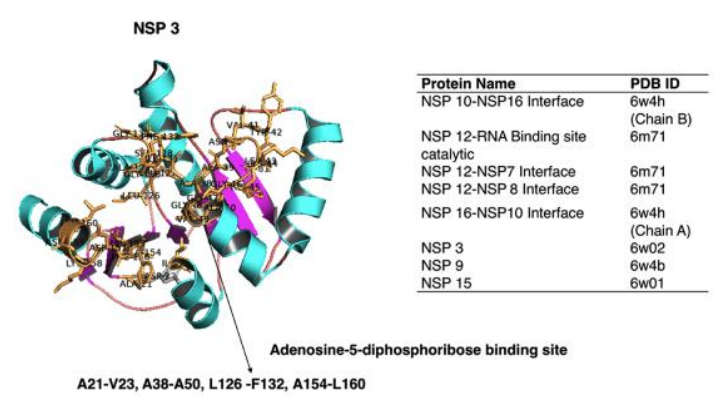

Figure 1. The cartoon representation of the NSP from SARS-CoV-2 showing the binding sites of the inhibitors. A) NSP10, B) NSP16, C) NSP9, D) NSP12 D1, E) NSP12 D2, F) NSP12 D3, G) NSP15, H) NSP3. The amino acid residues are represented by one letter code.

Results of RMSD, RMSF and Rg were plotted and have been illustrated in Figure 2. In the case of NSP10 (Figure 2A), slightly lower average RMSD value was obtained for N10P1 $(0.49)$ and N10R3 $(0.48)$ in comparison with NSP10 apo-protein $(0.51 \mathrm{~nm})$. The average RMSF fluctuations of residues were slightly lower for N10P1 and N10R3 $(\sim 0.2 \mathrm{~nm})$ in comparison to the apo-protein $(0.25 \mathrm{~nm})$. It can also be observed from Figure $2 \mathrm{~A}$ that N10P1 showed comparatively decreased fluctuation $(\triangle \mathrm{RMSF})$ in the residues interacting with the phytochemicals w.r.t. the apo-protein.

For NSP12d1 (Figure 2B) the average RMSD $(0.3 \mathrm{~nm}), \operatorname{RMSF}(0.16 \mathrm{~nm})$ and $\operatorname{Rg}(3 \mathrm{~nm})$ were similar to that of the apo-protein. The $\triangle \mathrm{RMSF}$ was lower for the phytochemical and repurposed drug interacting residues. For NSP12d2 (NSP12-NSP7 interface) the average RMSD $(0.3 \mathrm{~nm})$ were similar with the apo-protein for N12d1P2, N12d1P3, N12d1P4 and N12d1R6 compared to the slightly higher value obtained for N12d1P1 $(0.36 \mathrm{~nm})$. Similar trend in average RMSF and $\mathrm{Rg}$ were obtained N12d1 as evident from the $\triangle \mathrm{RMSF}$ and $\mathrm{Rg}$ plots illustrated in Figure 2C. In the case of N12d3 binding (Figure $2 \mathrm{D})$, the average RMSD $(0.27$ 
$\mathrm{nm})$, RMSF $(0.14 \mathrm{~nm})$ of N12d3P1 was slightly lower than the apo-protein, the other phytochemicals and the repurposed drug. The compactness of all the complexes were similar with average $\operatorname{Rg}(0.3 \mathrm{~nm})$. The compactness of all the simulated structures were similar with average $\operatorname{Rg}$ of $\sim 1.44 \mathrm{~nm}$.

In the case of NSP16 (Figure 2B) the lowest average RMSD was obtained for N16P2 $(0.28 \mathrm{~nm})$ compared to the apo-protein $(0.33 \mathrm{~nm})$. The average RMSF fluctuations of the phytochemicals were similar to that of the apo-protein $(\sim 0.15 \mathrm{~nm})$. It is to be noted here that the repurposed drug (N16R4) did not form stable complex with NSP16 after 20 ns of the MD simulation and thus was not analysed further. Lower fluctuations at the inhibitor interacting residues were obtained for the phytochemicals w.r.t. the apo-protein as shown by the $\Delta$ RMSF plot.

In the case of NSP15 (Figure 2 E), N15P1 showed comparable average RMSD, RMSF and Rg with the apo-protein. N15P2 and N15R2 did not form stable complex with NSP15 with very high average RMSD $(>0.7 \mathrm{~nm})$ and thus were not further analysed. N15P1 also showed decrease in fluctuations at the inhibitor binding site as evident from the the $\triangle$ RMSF plot.

In the case of NSP9 (Figure $2 \mathrm{~F}$ ), the phytochemicals showed comparable RMSD with an average of $\sim 0.3 \mathrm{~nm}$, average $\operatorname{RMSF}(0.17 \mathrm{~nm})$ and average $\mathrm{Rg}(1.4 \mathrm{~nm})$. The $\Delta$ RMSF plot showed lower fluctuations at the inhibitor interacting residue. Interestingly a lower dip in $\triangle$ RMSF was obtained for Phe76 for N9P2 and N9R4.

In the case of NSP3 (Figure 2G) the average RMSD of N3P1 was comparable to the apo-protein. The other phytochemicals and the repurposed drugs showed slightly higher RMSD. The $\triangle$ RMSF plot revealed that lowest fluctuations were obtained for residues 126-132. N3P4 and N3R5 showed higher fluctuations at residues 38-50. The average Rg was $2.4 \mathrm{~nm}$. It can be noted that the compactness of N3R4 started increasing after $60 \mathrm{~ns}$. 


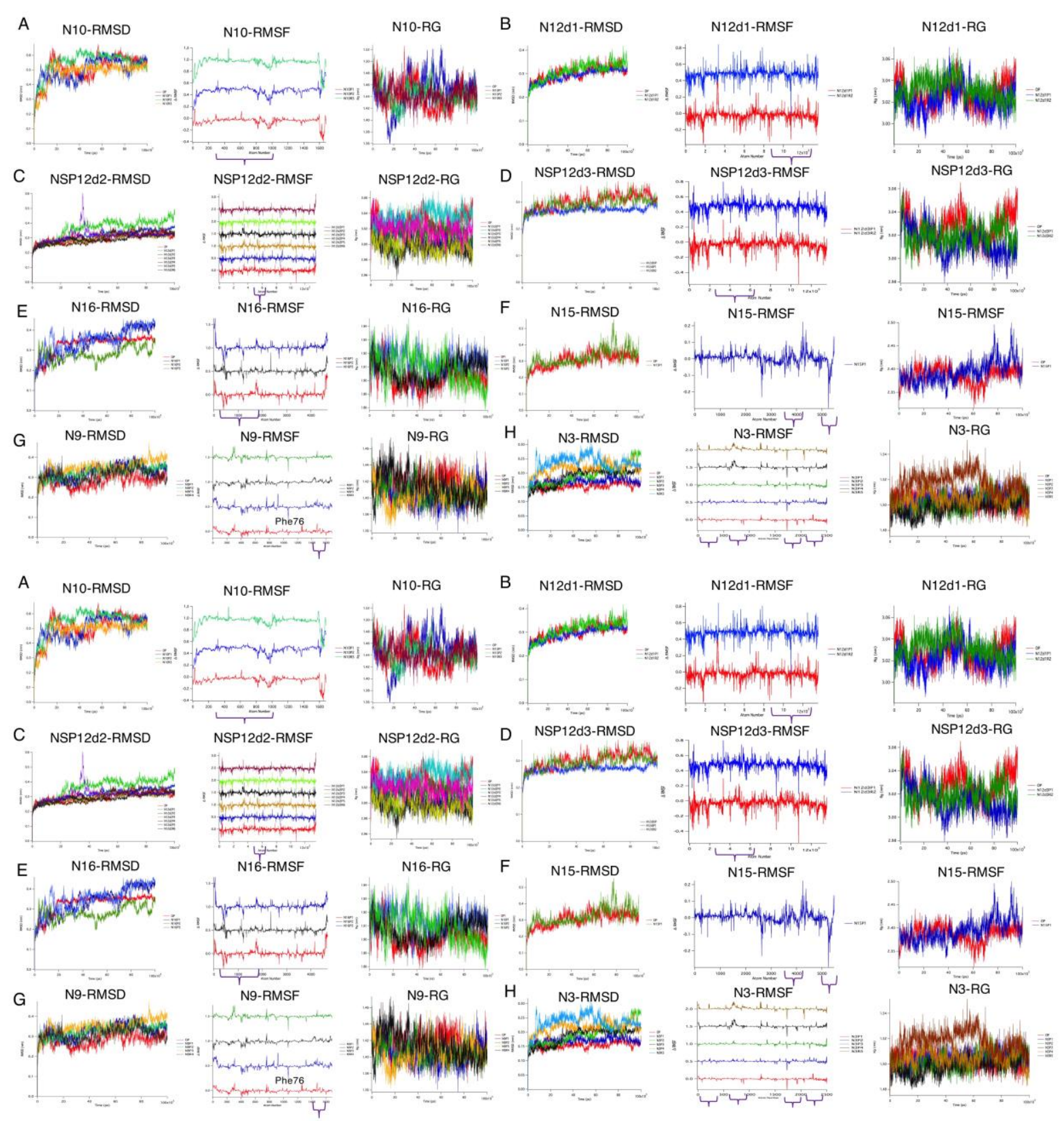

Figure 2. Comparative trajectory analysis of the 8 NSP binding sites with the phytochemicals and the repurposed drugs along with their apo-proteins. For abbreviations please refer main text and Table 1. A) NSP10, B) NSP12d1, C) NSP12d2, D NSP12d3, D) NSP16, E) NSP15, F) NSP9, G) NSP3. Purple brackets in $\triangle$ RMSF plots represent residue atom numbers interacting with the phytochemicals and the repurposed drugs (refer Figure 1). The atom numbering follows respective PDB structures.

\section{Trajectory analyses for relative free energy of binding and hydrogen bond occupancy of the NSP complexes}

The relative binding free energy were calculated for each complex of NSP using MM/PBSA. The standard errors were calculated by 500 steps of bootstrap analysis. It was observed that the relative binding free energies obtained for the complexes were in agreement 
with the RMSD, RMSF and Rg of their respective trajectories (Figure 2A). The computed lowest relative free energy of binding among all the complexes with respect to each NSP has been presented in Table 2. Interestingly repurposed drugs were computed to possess high relative free energy of binding with NSP3, NSP15 and NSP16. These complexes were thus not analysed further. Among all the complexes the phytochemical with the lowest relative binding energy $(<\sim-120 \mathrm{~kJ} / \mathrm{Mol})$ was obtained for N12d3P1, N3P1, N3P4 and N16P1. For the repurposed drug lowest relative binding free energy was obtained for N10R3 (-120 kJ/Mol) and N12d3R2 ( -223kJ/Mol). Interestingly among the NSP12 complexes the D3 site (NSP12NSP8 interface) showed better binding with phytochemicals and the repurposed drugs than the D1 (active site) and D2 (NSP12-NSP7 interface) sites. This reveals that NSP12-NSP8 interface is a good target site for drug targeting. NSP10-NSP16 interface and NSP3 also showed good binding energies with the phytochemicals. Whereas NSP15 showed the highest relative binding energies (worst performer in binding to phytochemicals and repurposed drugs) compared to the rest of the NSP analysed through this work.

Table 2: Relative lowest free binding energy calculated by MM/PBSA for each NSP

\begin{tabular}{|c|c|c|c|c|c|c|}
\hline Inhibitor & $\begin{array}{l}\text { van der Waal } \\
\text { energy } \\
(\mathrm{kJ} / \mathrm{Mol})\end{array}$ & $\begin{array}{l}\text { Electrostatic } \\
\text { energy } \\
(\mathbf{k J} / \mathrm{Mol})\end{array}$ & $\begin{array}{l}\text { Polar } \\
\text { solvation } \\
\text { energy } \\
(\mathbf{k J} / \mathbf{M o l})\end{array}$ & $\begin{array}{l}\text { SASA } \\
\text { energy } \\
(\mathbf{k J} / \mathrm{Mol})\end{array}$ & $\begin{array}{l}\text { Relative } \\
\text { Binding } \\
\text { Free } \\
\text { energy } \\
\text { (kJ/Mol) }\end{array}$ & $\begin{array}{l}\text { \#Residue } \\
\text { contribution } \\
\text { Binding } \\
\text { Free energy } \\
\text { (kJ/Mol) }\end{array}$ \\
\hline \multicolumn{7}{|c|}{ NSP 10} \\
\hline N10P1 & $\begin{array}{l}-184.657 \\
+/-20.543\end{array}$ & $\begin{array}{l}-5.743 \\
+/-4.589\end{array}$ & $\begin{array}{l}97.672 \\
+/-19.470\end{array}$ & $\begin{array}{l}-20.243 \\
+/-1.783\end{array}$ & $\begin{array}{l}-112.971 \\
+/- \\
16.527\end{array}$ & $\begin{array}{l}\text { Leu4345, } \\
\text { Ile4308, } \\
\text { Val4369 }\end{array}$ \\
\hline N10R3 & $\begin{array}{l}-177.662 \\
+/-18.014\end{array}$ & $\begin{array}{l}-4.835 \\
+/-5.206\end{array}$ & $\begin{array}{l}75.330 \\
+/-17.752\end{array}$ & $\begin{array}{l}-17.317 \\
+/-1.421\end{array}$ & $\begin{array}{l}-124.484 \\
+/- \\
25.220\end{array}$ & $\begin{array}{l}\text { Tyr4329, } \\
\text { Leu4345, } \\
\text { His4336 }\end{array}$ \\
\hline \multicolumn{7}{|c|}{ NSP12D1 } \\
\hline N12d1P1 & $\begin{array}{l}-124.475 \\
+/-21.162\end{array}$ & $\begin{array}{l}-5.636 \\
+/-4.267\end{array}$ & $\begin{array}{l}51.656 \\
+/-16.145\end{array}$ & $\begin{array}{l}-13.259 \\
+/-1.881\end{array}$ & $\begin{array}{l}-91.714 \\
+/- \\
16.660\end{array}$ & $\begin{array}{l}\text { Phe440, } \\
\text { Phe415, } \\
\text { Leu437 }\end{array}$ \\
\hline N12d1R2 & $\begin{array}{l}-96.233 \\
+/-13.862\end{array}$ & $\begin{array}{l}-3.993 \\
+/-2.454\end{array}$ & $\begin{array}{l}30.061 \\
+/-8.921\end{array}$ & $\begin{array}{l}-10.827 \\
+/-1.178\end{array}$ & $\begin{array}{l}-80.992 \\
+/ 13.123\end{array}$ & $\begin{array}{l}\text { Phe415, } \\
\text { Phe440, } \\
\text { Leu437 }\end{array}$ \\
\hline \multicolumn{7}{|c|}{ NSP12D2 } \\
\hline $\mathrm{N} 12 \mathrm{~d} 2 \mathrm{P} 4$ & $\begin{array}{l}-142.880 \\
+/-23.178\end{array}$ & $\begin{array}{l}-6.687 \\
+/-10.524\end{array}$ & $\begin{array}{l}72.704 \\
+/-36.840\end{array}$ & $\begin{array}{l}-16.064 \\
+/-2.008\end{array}$ & $\begin{array}{l}-92.926 \\
+/- \\
31.586\end{array}$ & $\begin{array}{l}\text { Lys } 798, \\
\text { Arg553, } \\
\text { Tyr455 }\end{array}$ \\
\hline N12d2R6 & $\begin{array}{l}-167.847 \\
+/-10.302\end{array}$ & $\begin{array}{l}-11.017 \\
+/-2.508\end{array}$ & $\begin{array}{l}108.884 \\
+/-10.887\end{array}$ & $\begin{array}{l}-15.784 \\
+/-0.797\end{array}$ & -85.765 & $\begin{array}{l}\text { Trp800, } \\
\text { Glu811, }\end{array}$ \\
\hline
\end{tabular}




\begin{tabular}{|c|c|c|c|c|c|c|}
\hline & & & & & $\begin{array}{l}+/- \\
13.760\end{array}$ & Trp617 \\
\hline \multicolumn{6}{|c|}{ N12D3 } & \\
\hline N12d3P1 & $\begin{array}{l}-169.341 \\
+/-18.584\end{array}$ & $\begin{array}{l}-2.053 \\
+/-3.186\end{array}$ & $\begin{array}{l}65.330 \\
+/-10.075\end{array}$ & $\begin{array}{l}-17.814 \\
+/-1.169\end{array}$ & $\begin{array}{l}-123.877 \\
+/- \\
15.553\end{array}$ & $\begin{array}{l}\text { Val398, } \\
\text { Val330, } \\
\text { Tyr273 }\end{array}$ \\
\hline N12d3R2 & $\begin{array}{l}-325.095 \\
+/-24.003\end{array}$ & $\begin{array}{l}-5.013 \\
+/-2.809\end{array}$ & $\begin{array}{l}138.228 \\
+/-\quad 11.958\end{array}$ & $\begin{array}{l}-30.849 \\
+/-1.728\end{array}$ & $\begin{array}{l}-222.729 \\
+/- \\
21.472\end{array}$ & $\begin{array}{l}\text { Phe396, } \\
\text { Tyr273, } \\
\text { Val675 }\end{array}$ \\
\hline \multicolumn{6}{|c|}{ NSP16 } & \\
\hline N16P1 & $\begin{array}{l}-152.891 \\
+/-23.291\end{array}$ & $\begin{array}{l}-1.058 \\
+/-4.995\end{array}$ & $\begin{array}{l}48.993 \\
+/-10.961\end{array}$ & $\begin{array}{l}-15.571 \\
+/-1.899\end{array}$ & $\begin{array}{l}-120.528 \\
+/- \\
23.072\end{array}$ & $\begin{array}{l}\text { Tyr6950, } \\
\text { Leu6898, } \\
\text { Phe6947 }\end{array}$ \\
\hline \multicolumn{6}{|c|}{ NSP9 } & \\
\hline N9P2 & $\begin{array}{l}-125.731 \\
+/-15.961\end{array}$ & $\begin{array}{l}-2.591 \\
+/-2.944\end{array}$ & $\begin{array}{l}37.451 \\
+/-11.636\end{array}$ & $\begin{array}{l}-13.235 \\
+/-1.491\end{array}$ & $\begin{array}{l}-104.106 \\
+/- \\
12.125\end{array}$ & $\begin{array}{l}\text { Leu113, } \\
\text { Phe76, } \\
\text { Leu104 }\end{array}$ \\
\hline N9R4 & $\begin{array}{l}-119.176 \\
+/-13.521\end{array}$ & $\begin{array}{l}-1.765 \\
+/-2.925\end{array}$ & $\begin{array}{l}30.670 \\
+/-8.861\end{array}$ & $\begin{array}{l}-12.280 \\
+/-1.230\end{array}$ & $\begin{array}{l}-102.552 \\
+/- \\
15.112\end{array}$ & $\begin{array}{l}\text { Leu104, } \\
\text { Leu113, } \\
\text { Leu107 }\end{array}$ \\
\hline \multicolumn{6}{|c|}{ NSP15 } & \\
\hline N15P1 & $\begin{array}{l}-128.354 \\
+/-16.899\end{array}$ & $\begin{array}{l}-6.799 \\
+/-8.384\end{array}$ & $\begin{array}{l}69.397 \\
+/-21.569\end{array}$ & $\begin{array}{l}-13.507 \\
+/-1.749\end{array}$ & $\begin{array}{l}-79.263 \\
+/- \\
15.485\end{array}$ & $\begin{array}{l}\text { Glu340, } \\
\text { Glu234, } \\
\text { His235 }\end{array}$ \\
\hline \multicolumn{6}{|c|}{ NSP3 } & \\
\hline N3P1 & $\begin{array}{l}-204.165 \\
+/-16.108\end{array}$ & $\begin{array}{l}-7.942 \\
+/-3.650\end{array}$ & $\begin{array}{l}107.923 \\
+/-13.714\end{array}$ & $\begin{array}{l}-21.812 \\
+/-0.982\end{array}$ & $\begin{array}{l}-125.995 \\
+/- \\
13.066\end{array}$ & $\begin{array}{l}\text { Phe132, } \\
\text { Ile131, } \\
\text { Val49 }\end{array}$ \\
\hline N3P4 & $\begin{array}{l}-183.720 \\
+/-23.432\end{array}$ & $\begin{array}{l}-12.307 \\
+/-4.755\end{array}$ & $\begin{array}{l}89.847 \\
+/-18.679\end{array}$ & $\begin{array}{l}-18.589 \\
+/-1.892\end{array}$ & $\begin{array}{l}-124.769 \\
+/- \\
16.441\end{array}$ & $\begin{array}{l}\text { Ile131, } \\
\text { Phe132, } \\
\text { Ala50 }\end{array}$ \\
\hline
\end{tabular}

For abbreviations please refer Table 1. The 500 step bootstrap +/- standard error have been presented. \#The top 3 contributing residues are arranged in descending order of the contribution to the binding energy.

Additionally, in order to understand the contribution of each residue of the NSPs towards the total relative binding free energy, decomposition of the energy for each residue was computed (Supplementary Table S1). The top 3 residues with the lowest relative free energy of binding have been presented in Table 2. Most of the residues in all the NSP complexes with lowest binding free energy were observed to be non-polar and aromatic.

Further, hydrogen bond (H-bond) occupancy was calculated over 100 ns trajectory for the complexes (Supplementary Table S2). Interestingly the residues with low relative free energy of binding were also with highest H-bond occupancy. In the case of NSP10 highest Hbond occupancy for N10P1 was obtained for Ile4308-CD atom (31.43\%). In N10R3, the atom- 
His4336-CA was with $24 \%$ occupancy. In the case of NSP12d1, occupancy of $21.4 \%$ was obtained for Leu437-N in N12d1P1 and Phe249 in N12d1R2 (23\%). In the case of N12d2, Ala550-N and Trp800-CD1 were with 30\% and 53\% occupancies for N12d2P4 and N12d2R6 respectively. In the case of N12d3P1 and N12d3R2, Tyr273-CB and Phe326-CB were with $31 \%$ and $57 \%$ occupancies respectively. From relative free energy and H-bond analysis of NSP12, it was realized that phytochemicals and repurposed drugs do not bind with the catalytic site residues S759-D761 for N12d1 and the NSP7 interacting interface (NSP12d2). However, it was realized that NSP12-NSP8 interface is a better target site for these phytochemicals and repurposed drugs as the residues involved in binding to NSP8 we also interacting with the phytochemicals and the repurposed drugs which also have the lowest relative free energy of binding. For NSP16P1, Tyr6950-CZ was with 33.2\% occupancy. The residues which are involved in high H-bond occupancy (Supplementary Table S2) are near the NSP16-NSP10 interface. In the case of N9P2 and N9R4, Ala108-CA (23\%) and Leu104-O (39\%) were with the highest H-bond occupancies respectively. These residues are present at the NSP9 dimerization interface (PDB ID: 6w4b). In the case of NSP15, His235-CB atom was with 31\% $\mathrm{H}$-bond occupancy. Thus the active site residues were involved in $\mathrm{H}$-bond with the phytochemicals. Finally, in the case of NSP3, N3P1 and N3P4, Leu126-CB (31\%) and Ile131CG2 (40\%) were with the highest H-bond occupancies. These residues interact with Adenosine5-Diphosphoribose in the crystal structure of NSP3 (6w02).

\section{Principal component and dynamic cross correlation matrix analysis of the NSP- phytochemical and repurposed drug complexes}

To extract the structural variations in details for the complexes with the lowest relative free energy of binding (Table 2), principal component analysis (PCA) on the Ca atom was performed and compared to their respective apo-proteins. The results of PCA corroborates with the RMSD, RMSF, Rg and relative binding free energy obtained for the phytochemicals and the repurposed drugs. The first two eigen vectors captured around $\sim 50 \%$ of the motions (Figure 3). In the case of NSP10 much larger conformational space was explored by N10P1 and N10R3 (Figure 3A). Their corresponding residue fluctuation plots showed overall lower RMSF for N10P1 and N10R3 compared to the apo-protein. In the case of NSP9 comparable conformational space were explored by the apo-protein and the complexes (Figure 3B). Residue fluctuation were lower for N9P2 compared to the apo-protein. However, increase in fluctuations were observed for N9R4 in comparison to the apo-protein. This indicates that binding of the phytochemical was more stabilizing than the repurposed drug. In the case of 
NSP15, N15P1 explored more conformational space (Figure 3C). Residue fluctuations were reduced in comparison to the apo-protein, showing creation of a stable environment upon ligand binding. In the case of N12d1 (Figure $3 \mathrm{D}$ ), more conformational space was explored by N12d1R2 in PC1. Comparable conformational space was explored by the apo-protein and the N12d1P1. Residue fluctuations were similar for N12d1P1 and N12d1R2 compared to the apo-protein (residues 500-800). Residue fluctuations were also similar in the case of N12d2 (residues 300-400) and N12d3 (200-500) at the ligand binding site in comparison to the apoprotein. In the case of NSP16 (Figure 3E), larger conformational space was explored by N16P1 compared to the apo-protein. Overall decrease in residue fluctuations were observed for N16P1. In the case of NSP3 similar conformational space was explored by N3P1 and N3P4 compared to the apo protein (Figure $3 \mathrm{~F}$ ). Slight decrease in residue fluctuations at the Cterminal was observed for N3P1. Residue fluctuations increased for N3P4 compared to N3P1 and apo-protein. Therefore, PCA showed overall reduction in residue fluctuations upon ligand binding for all the NSP complexes.
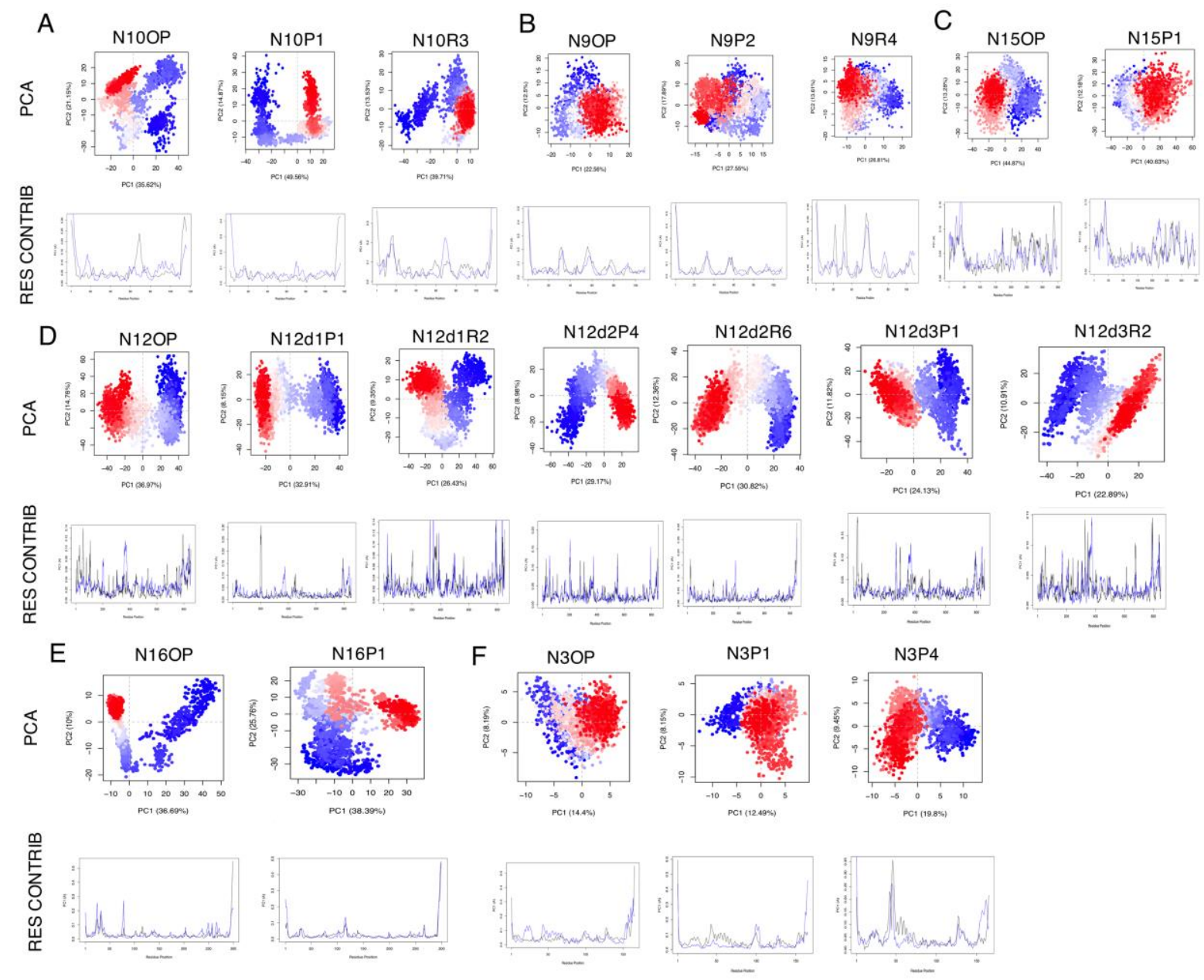
Figure 3. Comparative PCA of the 8 NSP binding sites with the phytochemicals and the repurposed drugs along with their apo-proteins (OP). The phytochemicals with the most negative free energy of binding have been illustrated here. The projection of PC1 on PC2. The continuous colour spectrum from blue to whit to red represents simulation time. The initial timescale represented by blue, intermediate by white and final by red. The RMSF of residue contribution to PCA. (black: PC1, blue: PC2). RES COBTRIB: Residue contribution to PCA (RMSF). For abbreviations please refer main text and Table 1. A) NSP10, B) NSP9, C) NSP15, D) NSP12d1, NSP12d2 and NSP12d3, E) NSP16, F) NSP3.
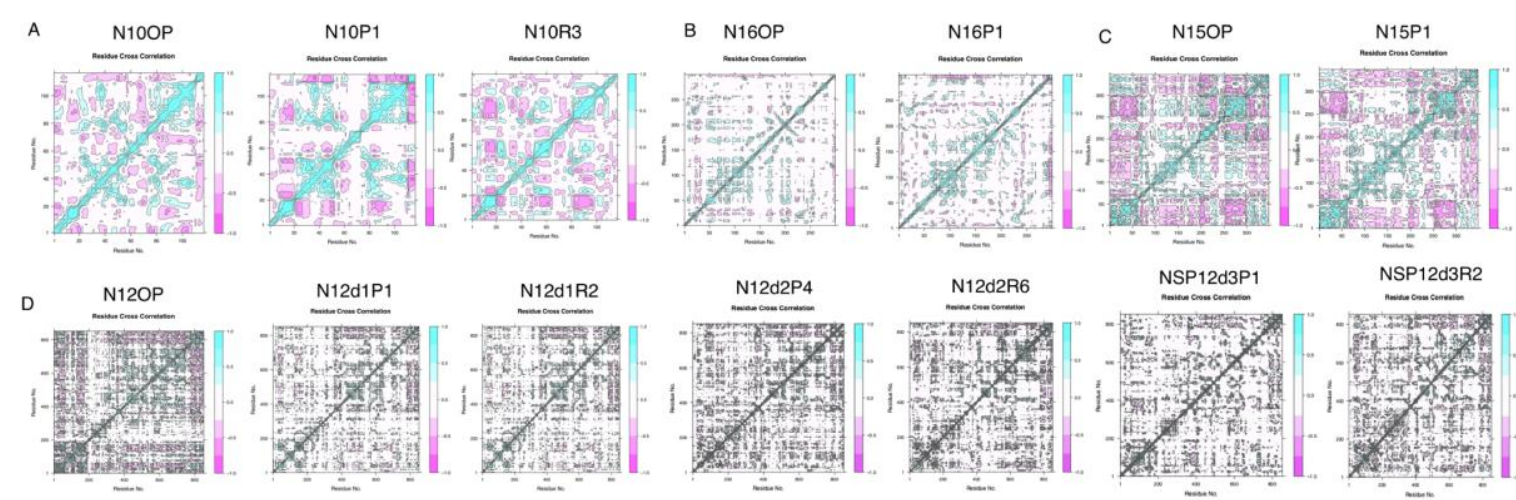

NSP12d3R2
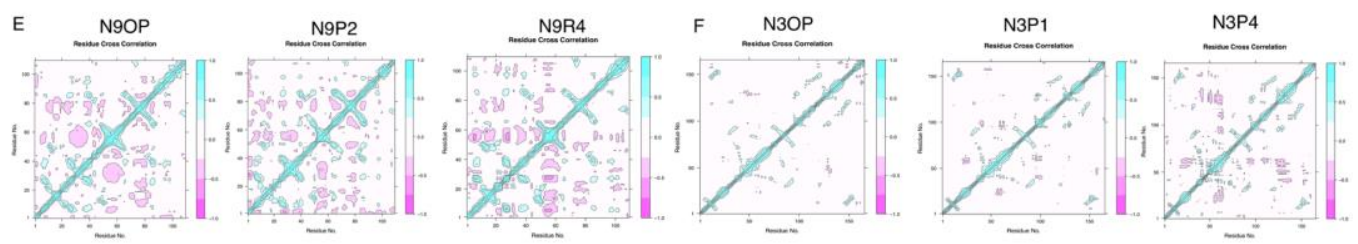

Figure 4. C) DCCM plots for 8 NSP binding sites with the phytochemicals and the repurposed drugs along with their apo-proteins (OP). The positive value represents the positively correlated motions (cyan), while negative values represent the anti-correlated motions (pink). For abbreviations please refer main text and Table 1. A) NSP10, B) NSP16, C) NSP15, D) NSP12d1, NSP12d2 and NSP12d3, E) NSP9, F) NSP3.

Further, dynamic cross-correlation matrix was computed by using the coordinates of $\mathrm{C} \alpha$ atoms from the trajectories. Dynamic cross correlation plots of the NSP complexes reveal that anti-correlation (indicative of ligand binding) slightly increased and correlation (indicative of stability upon ligand binding) increased at the binding sites on binding of phytochemicals and repurposed drugs in comparison to the apo-proteins. In case of NSP10 complex (Figure 4A), increase in correlation was more for N10P1 than N10R3. In case of NSP 16 (Figure 4B), N16P1 showed increased anti-correlation and correlation in comparison to the apo-protein. In the case of NSP15 (Figure 4 C), overall increase in correlated motion was observed. In case of NSP12- N12d1, N12d2 and N12d3 there was overall decrease in anti-correlated motions. In the case of NSP9 (Figure 4D) slight increase in anti-correlation was observed on ligand binding. In the case of NSP3 (Figure 4F), both anti-correlation and correlation increased on 
ligand binding compared to the apo-protein. Conclusively it can be inferred that ligand binding created a more stable environment in all the NSPs with respect to the apo-proteins.

\section{Biological pathway enrichment analysis of human protein targets identified for the phytochemicals}

To perform pathway enrichment analysis for the 22 phytochemicals, SwissTarget Database was used to retrieve the top 15 human protein targets for each phytochemical. The SARS-CoV-2 human protein targets were retrieved from literature survey (Zhou et al. 2020; Chakrabarty et al. 2020). Enrichr and REVIGO analysis (Kuleshov et al., 2016; Supek et al., 2011) of Gene Ontology enrichment of biological processes for phytochemicals and SARSCoV-2 with respect to p-value calculated with Fisher exact test has been presented in Figure 5 A-B respectively. Among the top $10 \mathrm{GO}$ biological processes cytokine mediated pathway and phosphorylation were with the most significant p-value for the SARS-CoV-2 and phytochemicals interacting with human protein targets respectively. Among the top 100 enriched GO terms- the biological processes common to both SARS-CoV-2 and phytochemicals were cytokine-mediated signalling pathway (GO:0019221), cellular response to cytokine stimulus (GO:0071345), positive regulation of macromolecule metabolic process (GO:0010604), interleukin-12-mediated signaling pathway (GO:0035722), cellular response to interleukin-12 (GO:0071349), MAPK cascade (GO:0000165), response to organic cyclic compound (GO:0014070), negative regulation of phosphoprotein phosphatase activity (GO:0032515) and JAK-STAT cascade (GO:0007259).

Interestingly, Enrichr analysis of KEGG pathway revealed that Influenza A and Epstein-Barr virus infection pathways were enriched for SARS-CoV-2 and the neuroactive ligand-receptor interactions were enriched for the phytochemicals. Again through VirusMint database enrichment analysis it was observed that the human protein targets of both SARSCoV-2 and the phytochemicals interacted with viral proteins from Human Immunodeficiency Virus I with the most significant p- value calculated with Fisher exact test (Figure 5 C-D). 
A
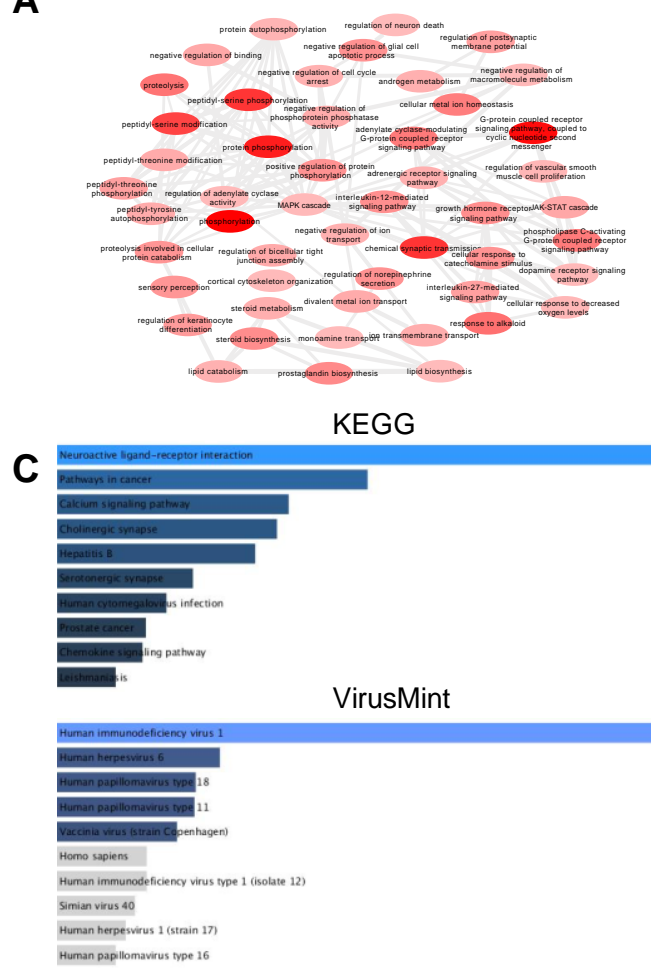

B

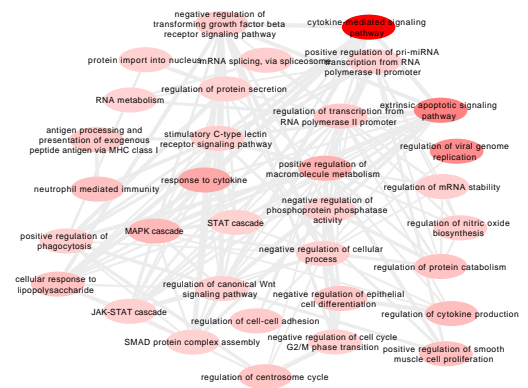

KEGG

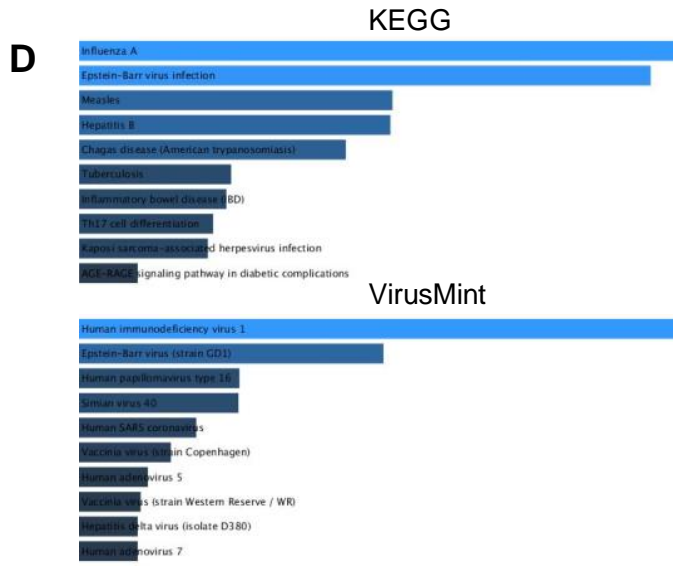

Figure 5. Enrichr analysis of biological processes enriched by the human proteins targets of A) phytochemicals and the B) SARS-CoV-2. The processes are colored based on the dispensability score obtained from REVIGO- higher scores are represented by darker shades of red (Supek et al., 2011).C) Top 10 KEGG pathway and VirusMint enrichment for phytochemicals. D) Top 10 KEGG and VirusMint enrichment for SARS-CoV-2. The bars in panel $\mathrm{C}$ and $\mathrm{D}$ represents the p-values computed using the Fisher exact test. The longer and lighter colored bars reflects that the term is more significant.

\section{Discussions}

COVID-19 pandemic causative agent SARS-CoV-2 is an RNA virus which codes for 16 non structural proteins (NSPs) from its ORF1a/b (Silva et al. 2020). Among the 16 NSPs, 6 NSP have been well characterized (NSP3, NSP9, NSP10, NSP12, NSP15 and NSP16) to play pivotal role in viral replication (Astuti et al. 2020). Therefore, these NSPs qualify as potential drug targets of SARS-CoV-2. It is believed that combination of drugs that can simultaneously target these NSPs will have higher possibility in combating COVID-19 infection. In our previous work we identified 18 different steroidal lactones from Withania sominifera and one each phytochemical from Solanum nigrum, Nigella sativa and Azadirachta indica, by virtual screening from 55 Indian medicinal plants, can be used to target these NSPs (Parida et al. 2020a). In the present work binding potential of these 22 phytochemicals and 10 repurposed drugs docked to 6 NSPs from SARS-CoV-2 were evaluated by employing 100 ns molecular 
dynamics simulation analysis. The results revealed the phytochemicals with the lowest binding energy against the 6 NSP targets were majorly from Withania sominifera. These phytochemicals thus have the potential for being developed into a concoction of natural drugs which can be used as prophylactic therapy for containing COVID-19 infections. Interesting observations were made while exploring the dynamic binding of the phytochemicals and repurposed drugs by RMSD, RMSF, Rg, PCA, DCCM, relative free energy of binding and hydrogen bond occupancy analyses. RMSD and RMSF were analysed as they reflect dynamic stability of the trajectory, necessary for obtaining good binding affinities (Dubey et al., 2013). $\mathrm{Rg}$ analysis reflects protein compactness which generally increase if binding with ligand forms a stable environment. High hydrogen bond occupancy is another parametric indicator of strong binding affinity (Khan et al. 2020). PCA and DCCM reflect overall conformational variance and atomic motions correlation upon ligand binding respectively (Islam et al., 2019; Hünenberger et al., 1995).

It was reported that in NSP3 (ATP ribose phosphatase of SARS-CoV-2), targeting the Adenosine-5-Diphosphoribose substrate binding site may result in enzyme inhibition (Wu et al. 2020). This work showed by MD simulation analysis of NSP3 complexes, 24,25dihydrowithanolide D and 27-Deoxy-14-hydroxywithaferin A formed more stable complex among the 4 phytochemicals and one repurposed drug (Baricitinib) analysed. Phe132, Ile131 in its active site pocket which forms hydrogen bond $(<\sim 3 \AA$ distance) with the Adenosine-5Diphosphoribose substrate, were with the lowest relative free energy of binding. Lowest RMSF fluctuations were also obtained for residues 126-132. Leu126 and Ile131 were also with the highest H-bond occupancies. Leu126 is also involved in non-bonded contacts with Adenosine5-Diphosphoribose C4' and C5' atoms at a distance of $\sim 3 \AA$. Both PCA and DCCM analysis revealed that ligand binding created a more stable environment.

It was also reported that inhibition of dimerization of NSP9 (important in viral replication) can lead to therapeutic benefits by affecting its RNA binding and SARS-CoV viral proliferation (Sutton et al., 2004; Frieman et al., 2012). It was reported that 97\% sequence identity is shared by NSP9 from SARS-CoV and SARS-CoV-2 (Littler et al. 2020). Interestingly, analysis of NSP9 complexes revealed that the phytochemical 12Deoxywithastramonolide and the repurposed drug Baricitinib were with the lowest relative free energy of binding. RMSD, RMSF, Rg were also stable for the complexes. PCA showed that the phytochemical complex has lower residue fluctuations compared to the repurposed drug. DCCM also showed slight increase in anti-correlation was observed on ligand binding. Interestingly a lower dip in $\triangle$ RMSF was obtained for Phe76. As Phe76 of one chain in NSP9 
is an important residue involved in inter-protein contact with Pro7 of another chain (PDB ID: $6 w 4 b)$. Thus its interaction with the inhibitors may affect protein dimerization. Further, interaction with the interface residues, Ala108 and Leu104 with the high H-bond occupancies and Leu113, Phe76 and Leu104 high affinity binding reflected by their binding free energy can affect dimerization with these compounds are primed with NSP9. Leu 104 is also part of the conserved protein-binding motif Gly100-Gly105 (Littler et al. 2020).

It was also reported that targeting the NSP10-NSP16 binding interface may result in attenuation of SARS-CoV-2 infection. NSP 10 is known to stimulate methyl transferase activity of NSP 16 in SARS-CoV (Bouvet et al. 2014). Therefore, similar role is expected in SARS-CoV-2 due to its shared sequence homology. It can be postulated that inhibiting the complex formation of NSP10-NSP16 will aid in containing the SARS-CoV-2 infection. 27Hydroxywithanolide B from Withania sominifera and Solvanol from Solanum nigrum were with the lowest relative free binding energies with NSP10 and NSP16 respectively. The repurposed drug Baricitinib also showed low relative free binding energy with NSP10. The RMSD, RMSF, Rg, PCA and DCCM analysis also corroborated with the relative free binding energy results reflecting on the stability of the compounds over $100 \mathrm{~ns}$ trajectories. The residues, with low relative binding free energy and involved with $\mathrm{H}$-bond with the compounds, lie at the NSP10-NSP16 binding interface and are also involved in Zinc coordination (H4336). Zinc coordination was reported to stimulate NSP16 activity in SARS-CoV (Bouvet et al. 2014). Similarly, residues in NSP16 at the NSP10-NSP16 interface were observed to form H-bonds with the compounds and have low relative free energy of binding. Thus phytochemicals interacting with these residues may interfere with the NSP10-NSP16 complex formation.

Further, targeting three sites of NSP12- RNA-dependent RNA polymerase (RdRp) involved in viral replication, revealed interesting results. The three sites targeted were the catalytic pocket, the NSP7-NSP12 and NSP8-NSP12 interfaces. The NSP12-NSP8 interface was realized to be the best binding site by lowest free energy obtained for Withaferin A and Lopinavir. Docking of Nsp8 to NSP12 was reported to be important in synthesis of the primer required for Nsp12-RdRp RNA synthesis (Wu et al. 2020). All the other trajectory analyses could be positively correlated to the computed relative free energy of binding for the NSP12 complexes.

MD simulation results of NSP15 (uridylate specific endoribonuclease) (Kim et al. 2020), showed that somniferine was with the lowest free energy of binding. The other trajectory analyses were in agreement with the obtained relative free energy of binding. The active site residues (His235) were involved in H-bond with the phytochemical and also positively 
contributed in lowering the relative free energy of binding. However, NSP15 showed the highest relative binding energies compared to the rest of the NSP analysed through this work. Thus it can be assumed to be a poor SARS-CoV-2 target in binding to these phytochemicals and repurposed drugs compared to the other NSPs.

Interestingly, through trajectory analysis for H-bond occupancies, lower occupancy of hydrogen bonds was observed in all the trajectories $(\sim<40 \%)$. This reveals that van der Waal's interactions were more pronounced in maintaining residue residue contacts in the NSP complexes rather than electrostatic interactions. This is also reflected by the much lower values of van der Waal's (vdW) energy than the electrostatic energy, contributing to the overall relative free binding energy. Therefore, it is seen that hydrophobic interactions are dominant in all complexes. High negative value of vdW energy represents greater hydrophobic interaction between the NSP complexes. This can be attributed to the presence of high number of non-polar residues at the binding sites of the 6 NSPs. Further, due to the presence of ergostane framework of steroidal lactone ring structures in the phytochemicals from Withania sominifera, that formed stable complexes with the NSPs, can also be related to lower hydrogen bond occupancy but higher prevalence of hydrophobic interactions. Interestingly, the repurposed drugs with good binding affinity also resembles the phytochemicals in having steroidal rings in their structures and more number of hydrogen bond acceptors than donors.

Additionally, enrichment of human biological pathway analysis was performed for the phytochemicals in comparison to the SARS-CoV-2 human protein targets. Interestingly the results revealed that pathways related to immunity, RNA virus mediated disease pathways and apoptosis were observed for both SARS-CoV-2 and the phytochemicals. This strongly implies that the action of phytochemicals in these pathways will be therapeutic in case of controlling COVID-19 infections. For example, biological process enrichment analysis revealed that Covid-19 targets the cytokine mediated pathway. This corroborates with precious report of COVID-19 association with "cytokine storms" including interleukin-6 (IL-6), interleukin 12 (IL-12), tumor necrosis factor alpha (TNF $\alpha$ ) and chemokines- causing damage to the host (Hirano et al. 2020). The biological process of phosphorylation associated with the phytochemicals corroborates with research where phytochemicals were reported to be protein modulators by potentiating signal transduction cascades (Frigo et al. 2002). Again the mitogenactivated protein kinase (MAPK) cascade was a common target for both SARS-CoV-2 and phytochemical associated human protein targets. The MAPK pathway is expressed in response to external stress such as viral infection and results in activation of p38 MAPK. This pathway also takes part in cell death and was reported to be activated by SARS-CoV (Mizutani, 2009). 
Phytochemicals have been previously reported to modulate MAPK signalling pathway mediated apoptosis (Kaur et al. 2016). Further inhibition of anus-kinase/Signal transducer and activator of transcription (Jak/STAT) cascade by drugs like Baricitinib and Ruxolitinib has been reported to control SARS-CoV infection (Author links open overlay panel (Giuseppe, 2020). Thus phytochemicals acting on this pathway can result in containing the SARS-CoV-2 infection. Furthermore, KEGG pathways enriched were Influenza A and neuroactive ligandreceptor interactions for the in SARS-CoV-2 and phytochemicals respectively. Association of SARS-CoV-2 protein targets with Influenza virus disease pathway was expected as both lead to severe respiratory diseases (Brand et al. 2014) reflecting the analysis accuracy. Interestingly, neuroactive ligand-receptor interactions are responsible to transmit signals for cell growth and survival. This pathway was reported to interact with Ebola virus transcription (Yu et al., 2018). Therefore, phytochemicals interacting with this pathway can be strongly assumed to control SARS-CoV-2 infections. Further, enrichment of VirusMint database resulted in human proteins that are targeted by Human Immunodeficiency Virus I for both the identified SARSCoV-2 and phytochemicals associated human protein targets. Cloaked similarity was reported for SARS-CoV and HIV-I infections (Kilger et al. 2003). Also there have been sporadic reports of phytochemicals in the control of HIV-I infections (Yoshiki et al. 2005). Further, anti-HIV drugs have been proposed to be effective against SARS-COV-2 (Martinez et al. 2020). This reflects that these phytochemicals can act as antivirals in not only controlling SARS-CoV-2 but with potential in acting against RNA viruses. Another interesting observation was negative regulation of phosphoprotein phosphatase activity being enriched for both SARS-CoV-2 and phytochemicals. Viruses use phosphoprotein phosphatase activity especially Phosphoprotein Phosphatase 2A to specifically weaken key survival pathways of their hosts (Guergnon et al. 2011). Thus, involvement of this biological process with SARS-CoV-2 and phytochemicals indicates that Phosphatase $2 \mathrm{~A}$ can be a potential drug target for controlling SARS-CoV-2 infections. A novel observation about phytochemical-SARS-CoV2-human systems was that the human proteins targeted were enriched in the regulation of metabolic processes. Metabolic processes like glycolysis have been reported to be targeted viruses (Durmuş Tekir et al. 2012). Therefore, metabolic pathways should be studied further to understand SARS-CoV-2 infection process in order to comprehend the effects of the phytochemicals in controlling the SARSCoV-2 infection. 


\section{Conclusions}

The ongoing SARS-CoV-2 pandemic makes us painfully realize that treating the infection is still a far-fetched goal. Therefore, any contribution in this direction may lead to development of a treatment regime for controlling the infection at an early stage. In this work stability of phytochemicals and repurposed drug complexes with 6 NSPs from SARS-CoV-2 were analysed by $100 \mathrm{~ns}$ MD simulations. Overall, the simulation run confirms the stability of interaction of phytochemicals from Withania sominifera with the 8 NSPs binding sites (three sites belonging to NSP12. Further, the important residues interacting with the phytochemicals showed that phytochemicals and repurposed drugs with steroidal moieties in their chemical structures formed stable interactions with the NSPs. Again, Human protein pathway analysis revealed that pathways related to immunity, RNA virus mediated disease pathways and apoptosis were enriched for both SARS-CoV-2 and the phytochemicals. Thus it can be said that the multi-potency of these phytochemicals can be used to regulate COVID-19 infection by targeting these pathways along with the NSPs. Conclusively this work warrants further study from the perspective of experimental validation to test the efficacy of these phytochemicals and the repurposed drug for the prevention and treatment of COVID-19.

\section{ACKNOWLEDGEMENTS}

This work used resources services, and support provided via the COVID-19 HPC Consortium (https://covid19-hpc-consortium.org/), which is a unique private-public effort to bring together government, industry, and academic leaders who are volunteering free compute time and resources in support of COVID-19 research. We would also like to acknowledge Noor Enzymes Private Limited for providing us with the human resources needed to successfully complete this work.

\section{Disclosure statement}

No potential conflict of interest was reported by the authors.

\section{Author contributions statement}

All authors conceived, conducted and analysed the results of experiments equally.

\section{Supplemental online material}

Supplemental data for this article is available online 


\section{ORCID}

Pratap Kumar Parida: 0000-0002-8193-335X

Dipak Paul: 0000-0002-5664-4601

Debamitra Chakravorty: 0000-0002-1520-0780

\section{References}

1. Chen, Y., Zhou, H., Zhou, Y., \& Zhou, F. (2020). Prevalence of self-reported depression and anxiety among pediatric medical staff members during the COVID-19 outbreak in Guiyang, China. Psychiatry Research, 288, 113005.

2. Guan, W. J., Ni, Z. Y., Hu, Y., Liang, W. H., Ou, C. Q., He, J. X., ... \& Du, B. (2020). Clinical characteristics of coronavirus disease 2019 in China. New England journal of medicine, 382(18), 1708-1720.

3. Huang, C., Wang, Y., Li, X., Ren, L., Zhao, J., Hu, Y., ... \& Cheng, Z. (2020). Clinical features of patients infected with 2019 novel coronavirus in Wuhan, China. The lancet, 395(10223), 497-506.

4. Deng, S. Q., \& Peng, H. J. (2020). Characteristics of and public health responses to the coronavirus disease 2019 outbreak in China. Journal of clinical medicine, 9(2), 575.

5. Jin, Y. H., Cai, L., Cheng, Z. S., Cheng, H., Deng, T., Fan, Y. P., ... \& Han, Y. (2020). A rapid advice guideline for the diagnosis and treatment of 2019 novel coronavirus (2019-nCoV) infected pneumonia (standard version). Military Medical Research, 7(1), 4.

6. Islam, M. T., Sarkar, C., El-Kersh, D. M., Jamaddar, S., Uddin, S. J., Shilpi, J. A., \& Mubarak, M. S. (2020). Natural products and their derivatives against coronavirus: review of the non-clinical and pre-clinical data. Phytotherapy Research.

7. Wu F., Zhao S., Yu B., Chen Y.-M., Wang W., Song Z.-G., Hu Y., Tao Z.-W., Tian J.H., Pei Y.-Y., Yuan M.-L., Zhang Y.-L., Dai F.-H., Liu Y., Wang Q.-M., Zheng J.-J., Xu L., Holmes E. C., \& Zhang Y.-Z. (2020). A new coronavirus associated with human respiratory disease in China. Nature, 579(7798), 265-269.

8. Amanat, F., \& Krammer, F. (2020). SARS-CoV-2 vaccines: status report. Immunity. Volume 52, Issue 4, 14 April 2020, Pages 583-589

9. COVID-19 vaccine tracker. https://www.raps.org/news-and-articles/newsarticles/2020/3/covid-19-vaccine-tracker

10. Denaro, M., Smeriglio, A., Barreca, D., De Francesco, C., Occhiuto, C., Milano, G., \& Trombetta, D. (2020). Antiviral activity of plants and their isolated bioactive compounds: An update. Phytotherapy Research, 34(4), 742-768.

11. Luo, H., Tang, Q. L., Shang, Y. X., Liang, S. B., Yang, M., Robinson, N., \& Liu, J. P. (2020). Can Chinese medicine be used for prevention of corona virus disease 2019 (COVID-19)? A review of historical classics, research evidence and current prevention programs. Chinese journal of integrative medicine, 26(4):243-250

12. Pang, J., Wang, M. X., Ang, I. Y. H., Tan, S. H. X., Lewis, R. F., Chen, J. I. P., ... \& $\mathrm{Ng}, \mathrm{X}$. Y. (2020). Potential rapid diagnostics, vaccine and therapeutics for 2019 novel coronavirus (2019-nCoV): a systematic review. Journal of clinical medicine, 9(3), 623.

13. Yang, Y., Islam, M. S., Wang, J., Li, Y., \& Chen, X. (2020). Traditional Chinese medicine in the treatment of patients infected with 2019-new coronavirus (SARS-CoV- 
2): a review and perspective. International journal of biological sciences, 16(10), 17081717

14. Zhang, D. H., Wu, K. L., Zhang, X., Deng, S. Q., \& Peng, B. (2020). In silico screening of Chinese herbal medicines with the potential to directly inhibit 2019 novel coronavirus. Journal of integrative medicine, 18(2), 152-158.

15. J. Zhenming, D. Xiaoyu, X. Yechun, D. Yongqiang, L. Meiqin, Z. Yao, Z. Bing, L. Xi aofeng, Z. Leike, P. Chao, et al.Structure of Mpro 1 from COVID-19 virus and discovery of its inhibitors. bioRxiv (2020), 10.1101/2020.02.26.964882

16. Parida, P. K., Paul, D., \& Chakravorty, D. (2020a). Nature to nurture- identifying phytochemicals from Indian medicinal plants as prophylactic medicine by rational screening to be potent against multiple drug targets of SARS-CoV-2. ChemRxiv. https://doi.org/10.26434/chemrxiv.12355937

17. Parida, P. K., Paul, D., \& Chakravorty, D. (2020b). The Natural Way Forward: Molecular Dynamics Simulation Analysis of Phytochemicals from Indian Medicinal Plants as Potential Inhibitors of SARS-CoV-2 Targets.

18. Pachetti, M., Marini, B., Benedetti, F., Giudici, F., Mauro, E., Storici, P., ... \& Zella, D. (2020). Emerging SARS-CoV-2 mutation hot spots include a novel RNA-dependentRNA polymerase variant. Journal of Translational Medicine, 18, 179.

19. Littler, D. R., Gully, B. S., Colson, R. N., \& Rossjohn, J. (2020). Crystal structure of the SARS-CoV-2 non-structural protein 9, Nsp9. Iscience, 23, 101258.

20. Fehr, A. R., Channappanavar, R., Jankevicius, G., Fett, C., Zhao, J., Athmer, J., ... \& Perlman, S. (2016). The conserved coronavirus macrodomain promotes virulence and suppresses the innate immune response during severe acute respiratory syndrome coronavirus infection. MBio, 7(6): e01721-16

21. Lei, J., Kusov, Y., \& Hilgenfeld, R. (2018). Nsp3 of coronaviruses: Structures and functions of a large multi-domain protein. Antiviral research, 149, 58-74.

22. Han, W., Li, X., \& Fu, X. (2011). The macro domain protein family: structure, functions, and their potential therapeutic implications. Mutation Research/Reviews in Mutation Research, 727(3), 86-103.

23. Cho, C. C., Lin, M. H., Chuang, C. Y., \& Hsu, C. H. (2016). Macro domain from Middle East respiratory syndrome coronavirus (MERS-CoV) is an efficient ADP-ribose binding module crystal structure and biochemical studies. Journal of Biological Chemistry, 291(10), 4894-4902.

24. Yoshimoto, F. K. (2020). The Proteins of Severe Acute Respiratory Syndrome Coronavirus-2 (SARS CoV-2 or n-COV19), the Cause of COVID-19. The Protein Journal, volume 39, pages 198-216

25. Sutton, G., Fry, E., Carter, L., Sainsbury, S., Walter, T., Nettleship, J., ... \& Siddell, S. (2004). The nsp9 replicase protein of SARS-coronavirus, structure and functional insights. Structure, 12(2), 341-353.

26. Frieman, M., Yount, B., Agnihothram, S., Page, C., Donaldson, E., Roberts, A., ... \& Baric, R. S. (2012). Molecular determinants of severe acute respiratory syndrome coronavirus pathogenesis and virulence in young and aged mouse models of human disease. Journal of virology, 86(2), 884-897.

27. Joseph, J.S., Saikatendu, K.S., Subramanian, V., Neuman, B.W., Brooun, A., Griffith, M., Moy, K., Yadav, M.K., Velasquez, J., Buchmeier, M.J. and Stevens, R.C., 2006. Crystal structure of nonstructural protein 10 from the severe acute respiratory syndrome coronavirus reveals a novel fold with two zinc-binding motifs. Journal of virology, 80(16), pp.7894-7901. 
28. Matthes, N., Mesters, J. R., Coutard, B., Canard, B., Snijder, E. J., Moll, R., \& Hilgenfeld, R. (2006). The non-structural protein Nsp10 of mouse hepatitis virus binds zinc ions and nucleic acids. FEBS letters, 580(17), 4143-4149.

29. Bouvet, M., Lugari, A., Posthuma, C.C., Zevenhoven, J.C., Bernard, S., Betzi, S., Imbert, I., Canard, B., Guillemot, J.C., Lécine, P. and Pfefferle, S., 2014. Coronavirus Nsp10, a critical co-factor for activation of multiple replicative enzymes. Journal of Biological Chemistry, 289(37), pp.25783-25796.

30. Chu, C. K., Gadthula, S., Chen, X., Choo, H., Olgen, S., Barnard, D. L., \& Sidwell, R. W. (2006). Antiviral activity of nucleoside analogues against SARS-coronavirus (SARS-CoV). Antiviral Chemistry and Chemotherapy, 17(5), 285-289.

31. Wu, C., Liu, Y., Yang, Y., Zhang, P., Zhong, W., Wang, Y., Wang, Q., Xu, Y., Li, M., Li, X. and Zheng, M., 2020. Analysis of therapeutic targets for SARS-CoV-2 and discovery of potential drugs by computational methods. Acta Pharmaceutica Sinica B. Volume 10, Issue 5, May 2020, Pages 766-788

32. Hackbart, M., Deng, X., \& Baker, S. C. (2020). Coronavirus endoribonuclease targets viral polyuridine sequences to evade activating host sensors. Proceedings of the National Academy of Sciences, 117(14), 8094-8103.

33. Decroly, E., Ferron, F., Lescar, J., \& Canard, B. (2012). Conventional and unconventional mechanisms for capping viral mRNA. Nature Reviews Microbiology, 10(1), 51-65.

34. Lindahl, Abraham, Hess, \& van der Spoel. (2020). GROMACS 2020.2 Source code. Zenodo.

35. Da Silva, A. W. S., \& Vranken, W. F. (2012). ACPYPE-Antechamber python parser interface. BMC Research Notes, 5, 367.

36. Darden, T., York, D., \& Pedersen, L. (1993). Particle mesh Ewald: An N · log (N) method for Ewald sums in large systems. The Journal of Chemical Physics, 98(12), 10089-10092.

37. Baker, N. A., Sept, D., Joseph, S., Holst, M. J., \& McCammon, J. A. (2001). Electrostatics of nanosystems: application to microtubules and the ribosome. Proceedings of the National Academy of Sciences, 98(18), 10037-10041.

38. Kumari, R., Kumar, R., Open Source Drug Discovery Consortium, \& Lynn, A. (2014). g_mmpbsa - A GROMACS tool for high-throughput MM-PBSA calculations. Journal of Chemical Information and Modeling, 54(7), 1951-1962.

39. Grant, B. J., Rodrigues, A. P., ElSawy, K. M., McCammon, J. A., \& Caves, L. S. (2006). Bio3d: an $\mathrm{R}$ package for the comparative analysis of protein structures. Bioinformatics, 22(21), 2695-2696.

40. Gfeller, D., Grosdidier, A., Wirth, M., Daina, A., Michielin, O., \& Zoete, V. (2014). SwissTargetPrediction: a web server for target prediction of bioactive small molecules. Nucleic Acids Research, 42(W1), W32-W38.

41. Zhou, P., Yang, X. L., Wang, X. G., Hu, B., Zhang, L., Zhang, W., Si, H. R., Zhu, Y., Li, B., Huang, C. L., \& Chen, H. D. (2020). A pneumonia outbreak associated with a new coronavirus of probable bat origin. Nature, 579(7798), 270-273.

42. Chakrabarty, B., Das, D., Bulusu, G., \& Roy, A. (2020). Network-based analysis of fatal comorbidities of COVID-19 and potential therapeutics. ChemRxiv. https://doi.org/10.26434/chemrxiv.12136470

43. Kuleshov, M. V., Jones, M. R., Rouillard, A. D., Fernandez, N. F., Duan, Q., Wang, Z., Koplev, S., Jenkins, S. L., Jagodnik, K. M., Lachmann, A., \& McDermott, M.G. (2016). Enrichr: a comprehensive gene set enrichment analysis web server 2016 update. Nucleic Acids Research, 44(W1), W90-W97. 
44. Supek, F., Bošnjak, M., Škunca, N., \& Šmuc, T. (2011). REVIGO summarizes and visualizes long lists of gene ontology terms. PLoS One 6, e21800.

45. Shannon, P., Markiel, A., Ozier, O., Baliga, N. S., Wang, J. T., Ramage, D., Amin, N., Schwikowski, B., \& Ideker, T. (2003). Cytoscape: a software environment for integrated models of biomolecular interaction networks. Genome Research, 13(11), 2498-2504.

46. Chatr-Aryamontri, A., Ceol, A., Peluso, D., Nardozza, A., Panni, S., Sacco, F., Tinti, M., Smolyar, A., Castagnoli, L., Vidal, M., \& Cusick, M. E. (2009). VirusMINT: a viral protein interaction database. Nucleic Acids Research, 37(suppl_1), D669-D673.

47. da Silva, S. J. R., da Silva, C. T. A., Mendes, R. P. G., \& Pena, L. (2020). Role of Nonstructural Proteins in the Pathogenesis of SARS-CoV-2. Journal of Medical Virology.

48. Astuti, I., \& Y srafil (2020). Severe Acute Respiratory Syndrome Coronavirus 2 (SARSCoV-2): An overview of viral structure and host response. Diabetes \& Metabolic Syndrome: Clinical Research \& Reviews, 14(4), 407-412.

49. Dubey K. D., Tiwari R. K., \& Ojha R. P. (2013). Recent advances in protein-ligand interactions: Molecular dynamics simulations and binding free energy. Current Computer-Aided Drug Design, 9(4), 518-531.

50. Khan, S. A., Zia, K., Ashraf, S., Uddin, R., \& Ui-Haq, Z. (2020). Identification of chymotrypsin-like protease inhibitors of SARS-CoV-2 via integrated computational approach. Journal of Biomolecular Structure and Dynamics. https://doi.org/10.1080/07391102.2020.1751298

51. Islam, M. J., Khan, A. M., Parves, M. R., Hossain, M. N., \& Halim, M. A. (2019). Prediction of deleterious non-synonymous SNPs of human STK11 gene by combining algorithms, molecular docking, and molecular dynamics simulation. Scientific Reports, 9, 16426.

52. Hünenberger, P. H., Mark, A. E., \& Van Gunsteren, W. F. (1995). Fluctuation and cross-correlation analysis of protein motions observed in nanosecond molecular dynamics simulations. Journal of Molecular Biology, 252(4), 492-503.

53. Kim, Y., Jedrzejczak, R., Maltseva, N.I., Wilamowski, M., Endres, M., Godzik, A., Michalska, K. and Joachimiak, A., 2020. Crystal structure of Nsp15 endoribonuclease NendoU from SARS-CoV-2. Protein Science.

54. Hirano, T., \& Murakami, M. (2020). COVID-19: A new virus, but a familiar receptor and cytokine release syndrome. Immunity. Volume 52, Issue 5, 19 May 2020, Pages 731-733

55. Frigo, D.E., Duong, B.N., Melnik, L.I., Schief, L.S., Collins-Burow, B.M., Pace, D.K., McLachlan, J.A. and Burow, M.E., 2002. Flavonoid phytochemicals regulate activator protein-1 signal transduction pathways in endometrial and kidney stable cell lines. The Journal of nutrition, 132(7), pp.1848-1853.

56. Mizutani, T. (2010). Signaling Pathways of SARS-CoV In Vitro and In Vivo. In Molecular Biology of the SARS-Coronavirus (pp. 305-322). Springer, Berlin, Heidelberg.

57. Kaur, M., Singh, R. P., Gu, M., Agarwal, R., \& Agarwal, C. (2006). Grape seed extract inhibits in vitro and in vivo growth of human colorectal carcinoma cells. Clinical Cancer Research, 12(20), 6194-6202.

58. Lippi, G., Sanchis-Gomar, F., \& Henry, B. M. (2020). Coronavirus disease 2019 (COVID-19): the portrait of a perfect storm. Annals of Translational Medicine, 8(7). 497 
59. van den Brand, J. M. A., Haagmans, B. L., van Riel, D., Osterhaus, A. D. M. E., \& Kuiken, T. (2014). The pathology and pathogenesis of experimental severe acute respiratory syndrome and influenza in animal models. Journal of comparative pathology, 151(1), 83-112.

60. Yu, D.S., Weng, T.H., Hu, C.Y., Wu, Z.G., Li, Y.H., Cheng, L.F., Wu, N.P., Li, L.J. and Yao, H.P., 2018. Chaperones, Membrane Trafficking and Signal Transduction Proteins Regulate Zaire Ebola Virus trVLPs and Interact With trVLP Elements. Frontiers in microbiology, 9, p.2724.

61. Kliger, Y., \& Levanon, E. Y. (2003). Cloaked similarity between HIV-1 and SARSCoV suggests an anti-SARS strategy. BMC microbiology, 3(1), 1-7.

62. Kashiwada, Y., Aoshima, A., Ikeshiro, Y., Chen, Y.P., Furukawa, H., Itoigawa, M., Fujioka, T., Mihashi, K., Cosentino, L.M., Morris-Natschke, S.L. and Lee, K.H., 2005. Anti-HIV benzylisoquinoline alkaloids and flavonoids from the leaves of Nelumbo nucifera, and structure-activity correlations with related alkaloids. Bioorganic \& medicinal chemistry, 13(2), pp.443-448.

63. Martinez, M. A. (2020). Compounds with therapeutic potential against novel respiratory 2019 coronavirus. Antimicrobial agents and chemotherapy, 64(5). e0039920

64. Guergnon, J., Godet, A. N., Galioot, A., Falanga, P. B., Colle, J. H., Cayla, X., \& Garcia, A. (2011). PP2A targeting by viral proteins: a widespread biological strategy from DNA/RNA tumor viruses to HIV-1. Biochimica et Biophysica Acta (BBA)Molecular Basis of Disease, 1812(11), 1498-1507.

65. Durmus Tekir, S., Cakir, T., \& Ulgen, K. (2012). Infection strategies of bacterial and viral pathogens through pathogen-human protein-protein interactions. Frontiers in Microbiology, 3, 46. 